\title{
Generation and analysis of large-scale expressed sequence tags (ESTs) from a full-length enriched cDNA library of porcine backfat
} tissue

\author{
Tae-Hun Kim*1, Nam-Soon Kim², Dajeong Lim³, Kyung-Tai Lee ${ }^{1}$, Jung- \\ Hwa Oh${ }^{2}$, Hye-Sook Park ${ }^{1}$, Gil-Won Jang1, Hyung-Yong Kim¹, Mina Jeon ${ }^{3}$, \\ Bong-Hwan Choi ${ }^{1}$, Hae-Young Lee ${ }^{1}$, HY Chung ${ }^{1}$ and Heebal Kim ${ }^{3}$
}

\begin{abstract}
Address: ${ }^{1}$ Division of Animal Genomics \& Bioinformatics, National LivestockResearch Institute, Rural Development Administration, Omokchundong 564, Kwonsun-gu, Suwon, Korea, ${ }^{2}$ Laboratory of Human Genomics, Genome Research Center, Korea Research Institute of Bioscience \& Biotechnology, Daejeon, Korea and ${ }^{3}$ School of Agricultural Biotechnology, Seoul National University San 56-1, Sillim-dong, Gwanak-gu, Seoul 151-742, Korea

Email: Tae-Hun Kim* - kth6160@rda.go.kr; Nam-Soon Kim - nskim37@kribb.re.kr; Dajeong Lim - greensea98@hanmail.net; KyungTai Lee - leekt@rda.go.kr; Jung-Hwa Oh - jhoh@kribb.re.kr; Hye-Sook Park - phs0724@rda.go.kr; Gil-Won Jang - kwchang@rda.go.kr; HyungYong Kim - yong27@biohackers.net; Mina Jeon - mhj617@snu.ac.kr; Bong-Hwan Choi - choibh@rda.go.kr; Hae-

Young Lee - leehy78@hanmail.net; HY Chung - chung133@rda.go.kr; Heebal Kim - heebal@snu.ac.kr

* Corresponding author
\end{abstract}

Published: 27 February 2006

BMC Genomics2006, 7:36 doi:10.1 I86/147I-2164-7-36

This article is available from: http://www.biomedcentral.com/I47/-2/64/7/36

(C) 2006Kim et al; licensee BioMed Central Ltd.

This is an Open Access article distributed under the terms of the Creative Commons Attribution License (http://creativecommons.org/licenses/by/2.0), which permits unrestricted use, distribution, and reproduction in any medium, provided the original work is properly cited.

\begin{abstract}
Background: Genome research in farm animals will expand our basic knowledge of the genetic control of complex traits, and the results will be applied in the livestock industry to improve meat quality and productivity, as well as to reduce the incidence of disease. A combination of quantitative trait locus mapping and microarray analysis is a useful approach to reduce the overall effort needed to identify genes associated with quantitative traits of interest.

Results: We constructed a full-length enriched cDNA library from porcine backfat tissue. The estimated average size of the cDNA inserts was $1.7 \mathrm{~kb}$, and the cDNA fullness ratio was $70 \%$. In total, we deposited 16, II0 highquality sequences in the dbEST division of GenBank (accession numbers: DT319652-DT335761). For all the expressed sequence tags (ESTs), approximately $10.9 \mathrm{Mb}$ of porcine sequence were generated with an average length of 674 bp per EST (range: 200-952 bp). Clustering and assembly of these ESTs resulted in a total of 5,008 unique sequences with I,776 contigs (35.46\%) and 3,232 singleton (65.54\%) ESTs. From a total of 5,008 unique sequences, $3,154(62.98 \%)$ were similar to other sequences, and I,854 (37.02\%) were identified as having no hit or low identity $(<95 \%)$ and $60 \%$ coverage in The Institute for Genomic Research (TIGR) gene index of Sus scrofa. Gene ontology (GO) annotation of unique sequences showed that approximately $31.7,32.3$, and $30.8 \%$ were assigned molecular function, biological process, and cellular component GO terms, respectively. A total of I,854 putative novel transcripts resulted after comparison and filtering with the TIGR SsGI; these included a large percentage of singletons $(80.64 \%)$ and a small proportion of contigs (13.36\%).

Conclusion: The sequence data generated in this study will provide valuable information for studying expression profiles using EST-based microarrays and assist in the condensation of current pig TCs into clusters representing longer stretches of CDNA sequences. The isolation of genes expressed in backfat tissue is the first step toward a better understanding of backfat tissue on a genomic basis.
\end{abstract}


Table I: Size distributions of the selected cDNA inserts.

\begin{tabular}{lcc}
\hline Size $(\mathrm{kb})$ & Number of clones* & Frequency $(\%)$ \\
\hline No insert & 45 & 4.7 \\
$<0.5$ & 45 & 4.7 \\
$0.5 \sim 1.0$ & 67 & 7.0 \\
$1.0 \sim 1.6$ & 441 & 45.9 \\
$1.6 \sim 2.0$ & 298 & 31.0 \\
$2.0 \sim 3.0$ & 107 & 11.2 \\
$3.0 \sim 4.0$ & 2 & 0.2 \\
Total & 960 & 100.0 \\
\hline
\end{tabular}

*The clones were selected from the non-normalised library.

\section{Background}

The breeding goals for pigs are largely directed towards retail carcass yield and meat quality because of the high economic value of these traits [1]. The marbling score, which is associated with the intramuscular fat (IMF) content, is one of the most important parameters for determining meat quality [2]. Backfat thickness (BFT) is moderately correlated with marbling traits [1]. BFT along with the average daily gain in mass have been the main selection traits among the finishing traits in the pig-breeding industry [1].

Quantitative trait locus (QTL) mapping and candidate gene analysis are currently being used to identify genes or markers associated with traits of economic interest. In the past decade, dozens of chromosome regions affecting traits related to fat deposition, such as IMF and BFT, in the pig have been reported using QTL mapping [51]. However, few of the genes controlling these QTL have been identified because a QTL may contain hundreds of potential polymorphic candidates.

The identification and localisation of genes expressed in tissues will enhance the selection and evaluation of candidate genes associated with QTL [3]. Expressed sequence tag (EST) projects provide a convenient and efficient approach for identifying and characterising the transcripts of genes expressed in tissues and cells. Moreover, the development of large-scale ESTs from various tissues has contributed to the construction of cDNA microarrays.

In pigs, the first EST project [4] and first large-scale EST project [5] have been reported. Subsequently, several research groups have generated ESTs from cDNA libraries constructed from various porcine tissues, such as anterior pituitary [6], backfat [7], brain [8], liver [9], skeletal muscle [10-12], orthopaedic implant-associated infection [13], and reproductive tissues [13-17].

Full-length cDNAs can be especially valuable resources for both functional genomics studies and the genomic structure of genes [18]. However, most porcine ESTs in public databases were derived from conventional cDNA libraries that have some drawbacks for isolating full-length cDNAs. In pigs, only two research groups have reported ESTs derived from full-length cDNA libraries constructed in the thymus, spleen, uterus, lung, liver, ovarian tissues, peripheral blood mononuclear cells [19], and olfactory bulbs [20]. However, ESTs generated from a full-length cDNA library constructed from backfat have not yet been deposited in a public database.

As a preliminary step towards developing large-scale EST sets expressed in adipose tissues and cells for the application of cDNA microarrays, we constructed a full-length enriched cDNA library from porcine backfat tissue using standard and normalised methods. In addition, we sequenced and characterised approximately 17,600 random clones.

\section{Results}

\section{Characterisation of a porcine backfat cDNA library}

To assess the quality of the full-length enriched cDNA library constructed from porcine backfat, the lengths and fullness ratios of cDNA inserts were investigated. As shown in Table 1, most of the cDNA insert sizes ranged from 1 to $3 \mathrm{~kb}$ based on 960 randomly selected clones from a non-normalised library. However, no cDNAs longer than $4 \mathrm{~kb}$ were found in these samples. The estimated average cDNA insert size of the library was $1.7 \mathrm{~kb}$.

To evaluate the normalised library, redundancy rates were calculated in a clustering analysis of all ESTs generated from the non-normalised and normalised library using the program CAP3 [25]. The calculated redundancy rates of the non-normalised and normalised library were 72.08 and $14.48 \%$, respectively. Although the redundancy rate of the normalised library was still high, it suggested that the library was successfully normalised.

In total, 300 sequences were randomly selected from the non-normalised library and compared to genes with e-values smaller than $e^{-100}$ in the nonredundant (nr) protein database of NCBI http://ncbi.nlm.nih.gov/ using a BLASTX search to determine the fullness ratios of the library. Of these 300 sequences, 154 (51.3\%) matched a known gene, and $70 \%$ of the clones of classified known genes were predicted to contain a putative ATG translation initiation

codon.

\section{Virtual expression analysis of porcine backfat tissue}

For an expression profile of backfat tissue, 1,331 contigs assembled from 13,991 high-quality ESTs from the nonnormalised library were analysed. Of these, the 38 most abundant transcripts observed in this library are listed in Table 2. The contig with the largest number of ESTs was identified to be mitochondrial solute carrier family 25 
member 6 (SLC25A6). Contigs with the second and third largest ESTs were eukaryotic translation elongation factor 1 gamma and actin (alpha skeletal muscle), respectively. Moreover, seven contigs of the 38 most abundant transcripts were related to the swine leukocyte antigen (SLA), especially SLA class I.

\section{Summary of the ESTs derived from a porcine backfat cDNA library}

Our analysis considered 16,110 high-quality EST sequences (phred quality $>20$ and at least $200 \mathrm{bp}$ ) consisting of 13,991 and 2,119 sequences derived from standard (15,360 clones) and normalised cDNA libraries (2,304 clones), respectively. All 16,110 sequences were deposited in the dbEST division of GenBank (accession numbers: DT319652-DT335761). For all ESTs, approximately $10.9 \mathrm{Mb}$ of porcine sequence were generated with an average length of 674 bp per EST (range: 200-952 bp).

Clustering and assembly of these ESTs resulted in a total of 5,008 unique sequences with 1,776 contigs $(35.46 \%)$ and 3,232 singleton (65.54\%) ESTs. All unique sequences were compared to the protein database of GenBank using BLASTX and were functionally annotated as proposed by TIGR.

Of the 5,008 unique sequences, 3,154 (62.98\%) were similar to other sequences, and 1,854 (37.02\%) were identified as having no hit or low identity $(<95 \%)$ and $60 \%$ coverage in the TIGR gene index of Sus scrofa.

\section{Gene Ontology annotation and bioinformatics analysis}

Mainly from pig EST data, The Institute for Genomic Research (TIGR) has produced the Pig Gene Index (SsGI). The TIGR gene indices are based on clustering of EST sequences, and the elements of a cluster are evaluated to produce a set of unique, high-fidelity virtual transcripts, called Tentative Consensus (TC) sequences [29]. To date, TIGR has assembled pig ESTs with pig transcripts into 38,781 TC sequences.

In total, 5,008 unique sequences consisting of 1,776 contigs and 3,232 singleton ESTs were assigned the Gene Ontology (GO) terms using sequence comparisons with the TIGR SsGI. Subsets of the unique sequences were annotated with the GO terms. Of the unique sequences, $31.7,32.3$, and $30.8 \%$ were assigned to molecular function, biological process, and cellular component GO terms, respectively. These are not mutually exclusive terms. Figure 1A shows the $2^{\text {nd }}$-level GO term distribution of the unique sequences. We compared the $2^{\text {nd }}$-level GO terms annotation of the TIGR SsGI and our unique sequences using Pearson's chi-square test (Figure 1B). Most of the terms in which the $p$-value showed significance were enriched in our unique sequences. This indi- cates that the normalisation and identification of new functional genes from our full-length cDNAs were very efficient. For example, chaperone regulator activity, the smallest child term $(0.03 \%)$ of molecular function in the TIGR SsGI, was enriched 39-fold $(1.17 \%)$ in our sequences.

A total of 1,854 putative novel transcripts resulted after the comparison and filtering with the TIGR SsGI. These included a large proportion of singletons $(80.64 \%)$ and a small percentage of contigs (13.36\%).

Of the 1,854 ESTs including 359 contigs and 1,495 singletons that had no hit or low identity $(<95 \%)$ at the TIGR gene index of S. scrofa, 48.98\% (908) had no significant hits to the nonredundant (nr) protein databases of the NCBI using a BLASTX search (e-value < 0.00001). As expected, this implied that most of the singletons with no BLAST hit are not genuine protein-coding sequences.

\section{Discussion}

Genome research in farm animals will expand our basic knowledge of the genetic control of complex traits, and the results will be applied in the livestock industry to improve meat quality and productivity, as well as to reduce the incidence of disease [30]. A combination of quantitative trait locus mapping and microarray analysis is a useful approach to reduce the overall effort needed to identify genes associated with quantitative traits of interest [31].

This is the first paper related to the construction and largescale EST analysis of a full-length enriched cDNA library from porcine backfat tissue. The estimated average cDNA insert size of this library was $1.7 \mathrm{~kb}$, which was no smaller than for other full-length cDNA libraries [20,32]. In addition, the fullness ratio was $70 \%$, which was similar to $60-$ $70 \%$ for full-length enriched cDNA libraries constructed using methods of selecting the cap structure $[21,22,33$ 37]. For the normalised library, the redundancy rate was reduced by approximately five times when the library was normalised in this study. Our result was similar to a reported reduction of 4.3 times [8]. The redundancy rate of ESTs from the non-normalised library was extremely high compared with those of the other cDNA libraries that have been constructed using our method (data not shown). The redundancy rate of the non-normalised library may still be high owing to the biological characteristics of porcine backfat tissue. As shown in Table 2, the 38 most abundant transcripts include $35.5 \%$ of the 13,991 ESTs generated from the non-normalised library. The library described was successfully normalised and proved to be an excellent resource for collecting unique transcripts expressed in porcine backfat tissue. In addition, these inserts were ligated unidirectionally into a pCNS-D2 
Table 2: Results of the BLAST search for contigs composed of the 38 most redundant ESTs in the non-normalised library from porcine backfat tissue

\begin{tabular}{|c|c|c|c|c|c|}
\hline \multirow[t]{2}{*}{ Contig (bp) } & \multirow[t]{2}{*}{ No of ESTs } & \multirow[t]{2}{*}{ Accession no } & \multirow[t]{2}{*}{ Species } & \multicolumn{2}{|l|}{ NCBI Blast } \\
\hline & & & & Gene name & e-value \\
\hline contig375 (983) & 685 & NM 214418 & Pig & Mitochondrial solute carrier family 25 member 6 & 0.0 \\
\hline contigl $036(940)$ & 350 & NM 001404 & Human & Eukaryotic translation elongation factor I gamma & 0.0 \\
\hline contig54 (' I,646) & 327 & NM 174225.I & Cattle & Actin, alpha skeletal muscle & 0.0 \\
\hline contig I $727(1,776)$ & 312 & $\mathrm{AF034253}$ & Pig & Sus scrofa mitochondrion, complete genome & 0.0 \\
\hline Contig I $227(1,442)$ & 293 & $\underline{X M 845314}$ & Dog & Eukaryotic translation elongation factor I alpha I & 0.0 \\
\hline contig265 (950) & 276 & AY459297.I & Pig & Sus scrofa MHC class I antigen (SLA-I), SLA-I*ms 2 allele & 0.0 \\
\hline contigl $55(1,589)$ & 241 & NM 005165 & Human & Aldolase C, fructose-bisphosphate & 0.0 \\
\hline contigl 336 (984) & 229 & NM 001014894.1 & Cattle & Ribosomal protein L4 & 0.0 \\
\hline contig34 (880) & 203 & NM 015710.3 & Human & Glioma tumor suppressor candidate region gene 2 protein $(p 60)$ & 0.0 \\
\hline contig I $237(1,230)$ & 178 & NM 002593.2 & Human & Procollagen C-endopeptidase enhancer & 0.0 \\
\hline contig $1086(1,358)$ & 168 & NM 003380.2 & Human & Vimentin & 0.0 \\
\hline contig944 (I,173) & 124 & NM 174049.1 & Cattle & Enolase I & 0.0 \\
\hline contigl III (964) & 112 & NM 001005726.1 & Pig & Annexin A2 & 0.0 \\
\hline contig324 (I, I73) & 112 & AF464013.1 & $\mathrm{Pig}$ & Sus scrofa MHC class I antigen (SLA-I), SLA-I*z allele & 0.0 \\
\hline contigl66I (913) & 104 & $\overline{\text { AY } 102469.1}$ & $\mathrm{Pig}$ & Sus scrofa MHC class I antigen (SLA-PI), SLA-PI*yn allele & 0.0 \\
\hline contigl 394 (899) & 85 & AYI35594.I & Pig & Sus scrofa MHC class I antigen (SLA-I), SLA-I*mel9 allele & 0.0 \\
\hline contig66I $(I, 167)$ & 81 & NM 006082.2 & Human & Tubulin alpha-I chain & 0.0 \\
\hline contig $1090(1,|4|)$ & 76 & NM 213920.1 & Pig & Decorin & 0.0 \\
\hline contig502 $(1,000)$ & 72 & NM 006088.5 & Human & Tubulin beta-2 & 0.0 \\
\hline contigl $688(881)$ & 69 & XM 614355 & Cattle & Bos taurus similar to heat shock protein, alpha-crystallin-related & 0.0 \\
\hline contig542 $(1,167)$ & 62 & NM 001154.2 & Human & Annexin A5 & 0.0 \\
\hline contig I 269 (873) & 57 & AF464005.I & Pig & Sus scrofa MHC class I antigen (SLA-B), SLA-B*y allele & 0.0 \\
\hline contig67। (876) & 56 & NM 182810.1 & Human & Cyclic-AMP-dependent transcription factor ATF-4 & 0.0 \\
\hline contigl60I $(1,220)$ & 55 & NM 174180.2 & Cattle & Short-chain dehydrogenase/reductase I & 0.0 \\
\hline contig7I $5(891)$ & 52 & NM 004925.3 & Human & Aquaporin 3 & 0.0 \\
\hline contig I 30 (873) & 49 & AF464059.2 & Pig & Sus scrofa MHC class I antigen (SLA-B), SLA-B*n allele & 0.0 \\
\hline Contig284 (95I) & 49 & NM 001035344 & Cattle & Bos taurus Mof4 family associated protein I (MRFAPI), & 0.0 \\
\hline contig I 92 (897) & 48 & NM 001013585.2 & Cattle & $\begin{array}{c}\text { Endothelial differentiation, sphingolipid G-protein-coupled } \\
\text { receptor, I }\end{array}$ & 0.0 \\
\hline contig848 (863) & 48 & NM $1747 \mid 5.1$ & Cattle & Ribosomal protein $\mathrm{L} 3$ & 0.0 \\
\hline contig549 (898) & 47 & NM 214276.1 & Pig & Citrate synthase & 0.0 \\
\hline contig86I (898) & 47 & XM 587033 & Cattle & Angiopoietin-like 4 & $8 e-109$ \\
\hline contig884 (896) & 47 & NM 001823.3 & Human & Creatine kinase, brain & 0.0 \\
\hline contig638 $(1,944)$ & 45 & NM 214246.1 & Pig & Carboxylesterase & 0.0 \\
\hline contig657 ( $(1,792)$ & 44 & NM 023948.3 & Human & Motile sperm domain containing 3 & 0.0 \\
\hline Contigl 616 (958) & 44 & Q9XSD9 & Pig & $\begin{array}{l}\text { PGS2_PIG (Q9XSD9) Decorin precursor (Bone proteoglycan II) } \\
\text { (PG-S2) }\end{array}$ & 0.0 \\
\hline contig939 (876) & 41 & A] 131112 & Pig & Sus scrofa MHC class I SLA genes, haplotype $\mathrm{HOI}$ & $5 e-119$ \\
\hline contig33 $(1,008)$ & 40 & NM 213774.1 & Pig & CD74 antigen & 0.0 \\
\hline contig8I7 $(2,268)$ & 40 & NM 006472.1 & Human & Thioredoxin interacting protein & 0.0 \\
\hline
\end{tabular}

plasmid vector [23] that can be expressed in mammalian cells. These clones could be readily used for expression and function studies, and will prove a valuable resource for functional genomics, as well as for genome annotation.

In this study, 16,110 high-quality ESTs were generated from 17,664 random clones and deposited into GenBank. To analyse the 16,110 ESTs efficiently, they were clustered into putative unique transcripts, and GO analysis was performed for functional studies. Sequences expressed in porcine backfat tissue contained a high percentage of chaperone regulator activity (39 times), antioxidant activity (4.9 times), translation regulator activity (3.7 times), and transporter activity (2.6 times) compared to total pig TCs in a molecular function category. Strangely, the GO terms of the viron and viral life cycle were significantly enriched in the backfat library compared with the SsGI. Backfat tissue consists of several different kinds of cell types and some studies have shown severe macrophage infiltration of obese adipose tissue $[49,50]$. Currently, we are reluctant to make hasty biological inferences from the 
data without validating it experimentally. Therefore, further study is needed to elucidate why the GO terms of the viron and viral life cycle are enriched in the backfat library. This suggests that ESTs deposited in the TIGR database were generated from various kinds of tissues or growth/developmental stages of a certain tissue or germinal cells. The percentage of sequences within different categories of the gene ontology index showed different distributions according to tissues used for the construction of the cDNA library $[12,17,20,38,39]$. Although our data are limited by the fact that this library was constructed from pooled samples collected at various growth stages, a functional categorisation of ESTs with known gene matches underlines general differences in the expression profiles of different tissues.

To identify novel sequences, the sequences of SsGI (ver 11.0) and our unique sequences were compared using the stand-alone BLAST program (ver 2.29) of NCBI. As a result, we obtained 1,854 putative novel transcripts with no BLAST hits. Novel transcripts may be expressed differently among tissues. In particular, we suggest that many of the novel transcripts observed in this study are expressed only in backfat tissue. However, we suggest that a large number of novel transcripts resulted from the lack of ESTs derived from porcine backfat tissue in the TIGR database. Moreover, several porcine ESTs in the TIGR SsGI were generated based on $3^{\prime}$ end sequencing, while our sequences were produced from the $5^{\prime}$ end. Sequence information for a certain EST in the TIGR database may show insufficient overlap between our sequences and sequences in the TIGR database to identify high similarity, although the two sequences may actually represent the same gene.

To date, approximately 400,000 ESTs derived from porcine tissues have been deposited in public databases. TIGR released SsGI ver 11.0 (18 January 2005), which consists of 38,781 TC sequences, 65,000 singleton ESTs, and 546 singleton ETs generated from approximately 400,000 ESTs. However, relatively few ESTs derived from porcine backfat tissue are stored in public databases. Before our study, 298 ESTs from porcine backfat tissue were assigned to a porcine radiation hybrid map [7]. Only 49 ESTs generated from a cDNA library from porcine backfat tissue and 54 ESTs derived from a cDNA library constructed from porcine longissimus dorsi muscle and backfat tissue have been deposited in GenBank. By contrast, approximately 130,000 ESTs generated from a full-length cDNA library are available from GenBank, and the Pig EST data explorer (PEDE) provides 68,076 ESTs consisting of 5,546 contigs and 28,461 singletons from full-length cDNA libraries constructed from various tissues [19]. However, ESTs derived from a full-length cDNA library constructed from porcine backfat tissue have not yet been deposited in public databases.
The most abundant transcript in porcine backfat tissue, which represented $4.9 \%$ of the ESTs derived from the nonnormalised library, was the mitochondrial solute carrier family 25 member 6 , which plays a fundamental role in cellular energy metabolism (Table 2). The most abundant transcripts expressed in backfat tissue were also expressed in olfactory bulbs of 5-week-old pigs [20]. Mitochondrial solute carrier family 25 member 6 was also the most abundant transcript in the olfactory bulbs of 5-week-old pigs. The expression of this gene has been reported to decrease when the cells are induced to differentiate in humans [40]. The most abundant genes were related to proteins involved in cell structure, cell growth, and basic cell functions. Elongation factor 1, which is essential for protein synthesis, was the fourth most abundant transcript. It was expressed secondarily in porcine Peyer's patch [39]. Seven of the 38 most abundant genes were related to SLA. The nomenclature for factors of the SLA class-I system [48] classifies them into four alleles (SLA$1{ }^{*} \mathrm{w} 13 \mathrm{~ms} 21$ ， SLA- $1{ }^{*} \mathrm{w} 08 \mathrm{sz} 01, \quad$ SLA- $1{ }^{*} \mathrm{w} 11 \mathrm{yn} 01$, SLA$1{ }^{*}$ w09ms09) in class- 1 group, two alleles (SLA- ${ }^{*} 05$ sy01, SLA- ${ }^{*}{ }^{*} 09$ sn01) in class- 2 group, and one allele (SLA$\left.3^{*} 0101\right)$ in class-3 group of SLA class I. Of these, SLA$1{ }^{*} \mathrm{w} 13 \mathrm{~ms} 21$ is the most abundantly expressed SLA allele in backfat tissue. The swine leukocyte antigen is also the most abundantly expressed transcript in oocytes during embryogenesis in pigs [17]. Vimentin, which encodes an intermediate filament protein, was the tenth most abundant transcript in our study. The frequency of sequences obtained for a particular gene is proportional to the level of expression of that gene because all sequences were obtained through random selection of clones [42,43]. By contrast, a total of 1,651 unique sequences with 270 contigs and 1,651 singlets were generated from 2,269 highquality sequences from 2,302 clones of the normalised library. Thirty-eight of the 270 contigs assembled three or more sequences, of which the most abundant transcript composed of 8 ESTs was matched with haplotype H01 of SLA class I (AJ131112). Moreover, 9 of 38 contigs were not observed in sequences generated from the non-normalised library, of which five contigs were putative noble transcripts and the others were matched with ITBA1 pro-

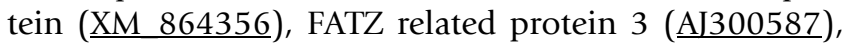
bone morphogenetic protein 7 precursor (NM_001719), and growth factor (NM_005262). However, we did not find backfat-specific ESTs among the abundantly expressed transcripts in the normalised library.

DNA microarray technology is a useful tool for studying the expression of a large number of genes in a particular tissue or cell type and allows an efficient, objective, and quantitative evaluation of genes in the QTL. It has the potential to reduce the overall effort needed in identifying genes causally associated with quantitative traits of interest $[31,44]$. 

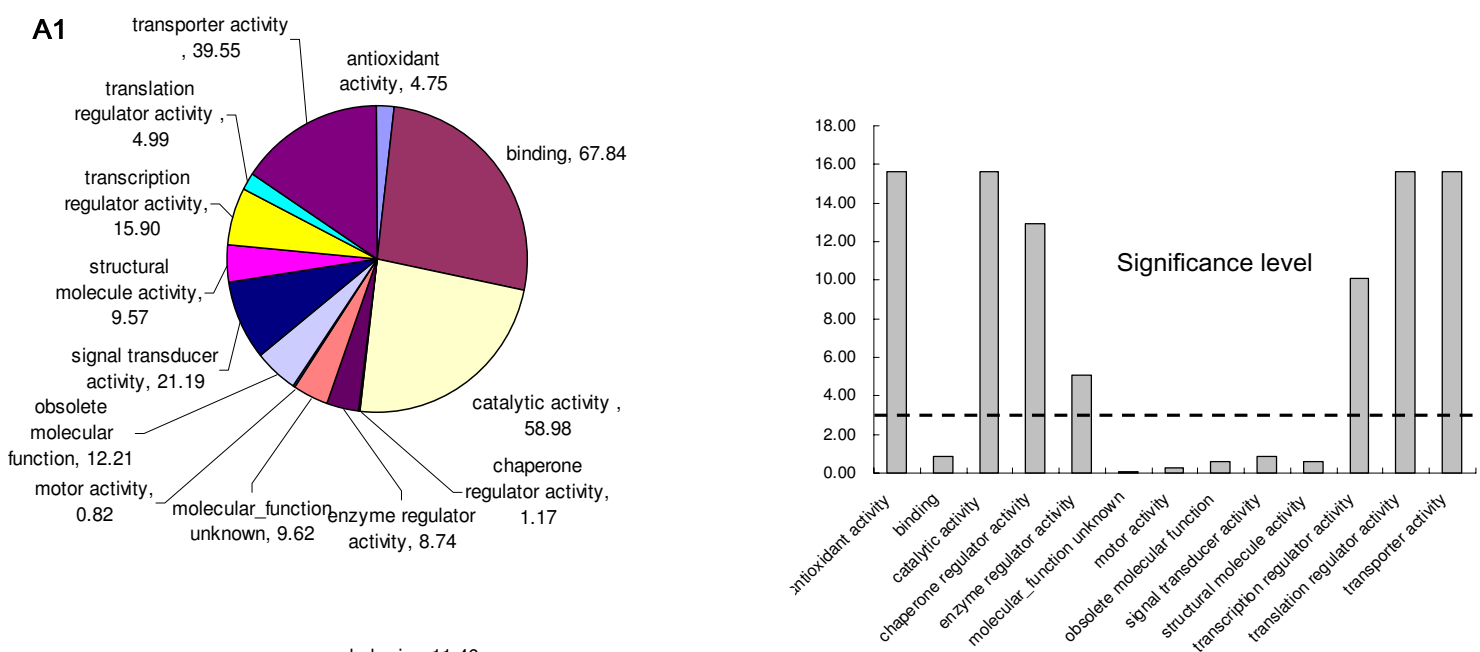

A2
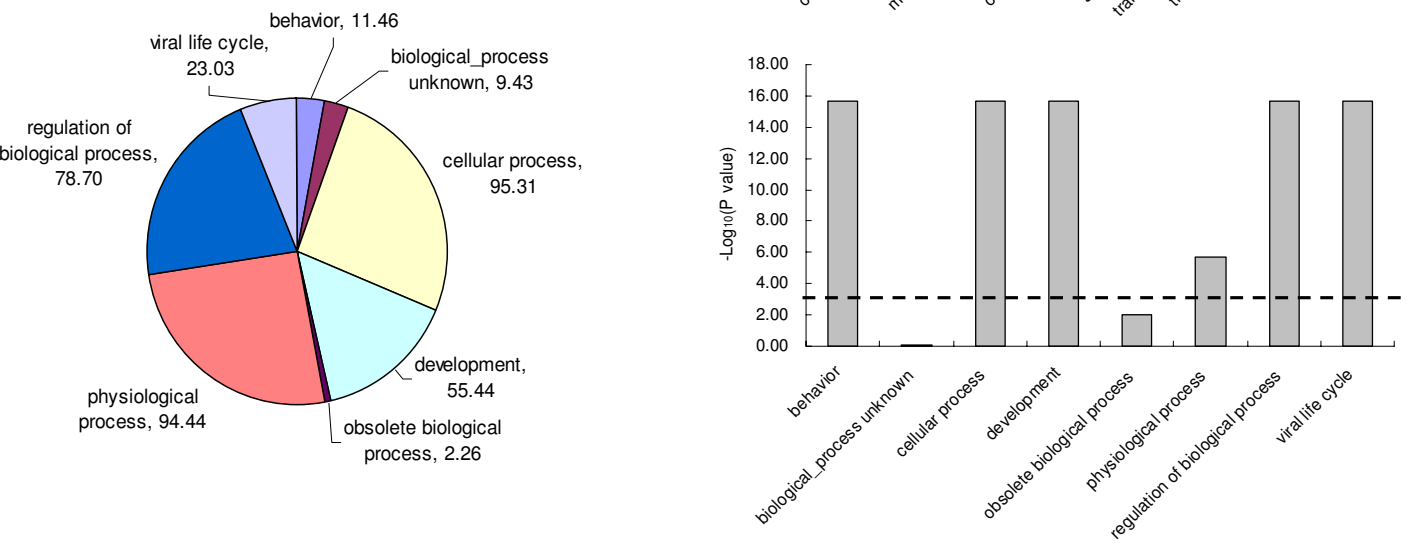

A3
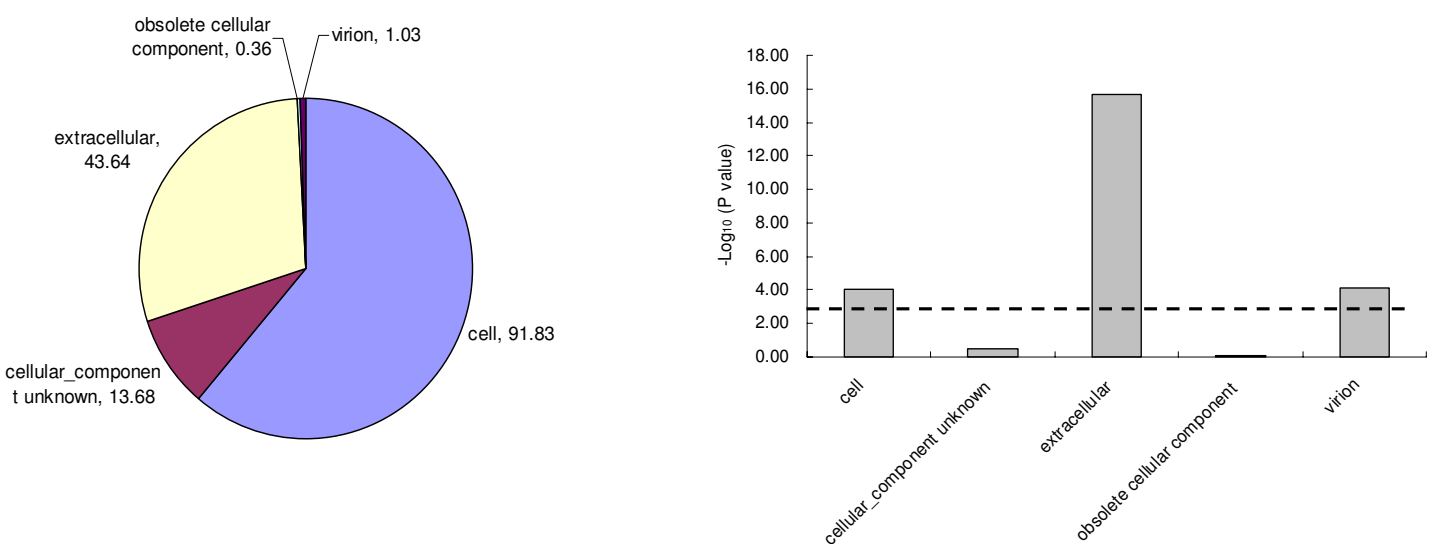

Figure I

Gene Ontology annotation of the porcine backfat transcripts $(A)$, andPearson's chi-square test of independence between the backfat transcripts and the TIGR SsGI (B). AI, A2 and A3 indicate molecular function, biological process, and cellular component, respectively. The overall significance level of alpharesulted from a Bonferroni correction, alpha $=0.5 / \mathrm{m}$, where $\mathrm{m}=30$, as 30 GO terms were compared between backfat and the novel transcripts. The dotted line indicates the significance level. 
To date, porcine cDNA microarrays have been reported using EST sets derived from skeletal muscle [45], whole embryo and adult skeletal muscle, and differential display PCR products from foetal and postnatal muscle [41], brain [8], small intestine [46], and ovarian follicle [47]. More recently, oligonucleotide arrays, such as QIAGEN Array-Ready Oligo Set for the Pig Genome (version 1.0), the Pig Genome Oligo Extension Set (version 1.0), and the Affymetix GeneChip Porcine Genome Array, representing 20,201 genes, have been made available commercially. However, large-scale EST data sets are essential resources for constructing comprehensive cDNA or oligonucleotide arrays. Therefore, the EST information generated in this study will be valuable for studying expression profiles using EST-based microarrays and will assist in the condensation of current pig TCs into clusters representing longer stretches of cDNA sequences.

In conclusion, approximately $70 \%$ of the full-length enriched cDNA library of porcine backfat tissue constructed in this study consisted of full-length cDNAs. Moreover, because pCNS-D2, the plasmid vector used for this library, can be expressed in mammalian cells, these clones could be used readily for expression and function studies. These sequence data will provide valuable information for identifying porcine genes expressed in backfat tissue. The isolation of genes expressed in backfat tissue is the first step towards a better understanding of backfat tissue on a genomic basis. The nonredundant ESTs generated from this library will allow us to construct cDNA microarrays for expression assays and to localise them onto a physical map for assessing genes that regulate fat accumulation in backfat tissue and further affect meat quality in pigs. Moreover, these expressed sequences will contribute towards expanding the comparative map between the pig and mammals such as humans and mice that have well characterised genomes.

\section{Methods}

\section{Sample preparation and total RNA extraction}

Four Landrace $\times$ Large White crossbred pigs were slaughtered at $1,7,12,18$, and 24 weeks of age to maximise the discovery of backfat expressed genes, as well as to identify nucleotide sequence variation for future studies. The backfat was excised immediately after slaughtering, snap frozen in liquid nitrogen, and stored at $-70^{\circ} \mathrm{C}$ until RNA was extracted. Total RNA was extracted from all the samples using an RNeasy Lipid Tissue Midi Kit (Qiagen, Valencia, CA, USA) as per the manufacturer's instructions.

\section{Full-length enriched cDNA library construction}

To construct a full-length enriched cDNA library, the prepared total RNA was pooled with the same amount of each sample. A full-length enriched cDNA library was constructed as previously described [21]. Briefly, $100 \mu \mathrm{g}$ of total RNA were treated with bacterial alkaline phosphatase (TaKaRa, Tokyo, Japan) and then with 100 units of tobacco acid pyrophosphatase (Waco, Tokyo, Japan). The pretreated total RNA was ligated with $0.4 \mu \mathrm{g}$ of $5^{\prime}$ ligoribonucleotide (5'-AGC AUC GAG UCG GCC UUG UUG GCC UAC UGG-3'). After completing the oligo capping reactions, mRNA was isolated using an Oligotex Mini Kit (Qiagen). The synthesis of first-strand cDNA from the purified mRNA and the cDNA amplification were performed as previously described [22]. The amplified PCR products were then digested with $S$ fiI, and cDNAs longer than $1.3 \mathrm{~kb}$ were ligated into DraIII-digested pCNS-D2 [23] in an orientation-defined manner. The ligated cDNA was then transformed into Escherichia coli Top 10F' (Invitrogen, Carlsbad, CA, USA) by electroporation (Gene Pulser II; BioRad, Hercules, CA, USA). The constructed cDNA library was normalised as previously described [24]. Consequently, two libraries were constructed from the same porcine backfat sample: a full-length cDNA library and a normalised full-length cDNA library.

\section{Plasmid isolation and cDNA sequencing}

Colonies were picked randomly, inoculated into individual wells of 96-deep well plates containing $1 \mathrm{~mL}$ of LB media and incubated at $37^{\circ} \mathrm{C}$ for $18 \mathrm{~h}$. Plasmid DNAs were extracted using a Montage Plasmid Miniprep 96 Kit (Millipore, Billerica, MA, USA) according to the manufacturer's instructions. The cDNA inserts were sequenced once from the $5^{\prime}$ end of clones using a BigDye Terminator Sequencing Kit ver 3.1 (Applied Biosystems, Foster City, CA, USA) and a 3730 DNA Analyser (Applied Biosystems).

\section{Characterisation of the full-length enriched cDNA library}

To evaluate the quality of the full-length enriched cDNA library constructed in this study, the lengths and fullness ratios of the CDNA inserts were investigated. In total, 960 clones were selected from the library randomly, and plasmid DNAs were extracted and digested with EcoRI and NotI restriction enzymes. Size fractionation was performed in a $1 \%$ agarose gel containing ethidium bromide.

We selected 300 sequences to determine the fullness ratios of the library. The sequences were compared to the nonredundant (nr) protein database at the National Center for Biotechnology Information (NCBI; http:// ncbi.nlm.nih.gov/) using a BLASTX search. Sequences matching the genes with an e-value smaller than $e^{-100}$ were selected, and then we evaluated whether a putative translation start site existed in these sequences. When a sequence contained a putative translation initiation codon, the sequence was defined as a full-length cDNA. 


\section{Sequence data analysis and EST clustering}

The porcine EST trace data were base-called using the program phrep [25] from trace chromatogram data of 5' EST sequences. The EST reads were quality trimmed using the phred quality score at a position where five ambiguous bases (phred quality $>2$ and at least $200 \mathrm{bp}$ ) were found within 15 consecutive bases. The vector sequences of the base-called EST data were clipped. The porcine EST data described here have been submitted to the GenBank database. The EST sequences were clustered and assembled using the cross-match program and the program CAP3 [26].

\section{Gene Ontology annotation and bioinformatics analysis}

To classify our ESTs and unique sequences using Gene Ontology (GO) terms, we downloaded The Institute for Genomic Research (TIGR) Pig Gene Index (SsGI; Release 11.0). A sequence similarity comparison between the Tentative Consensus (TC) sequences of the SsGI and our sequences was performed using the stand-alone BLAST program of NCBI (version 2.2.9), with 95\% identity and a 500-bit score as the cutoff values. The unique sequences were categorised using terms from the GO database. Since a large portion of these pig sequences has not yet been annotated, gene annotation was performed by extracting information with the term already annotated. Pearson's chi-square test was used to test the significance of which GO terms were enriched in one data set, but relatively depleted in the other. We compared the $2^{\text {nd }}$-level GO terms of the TIGR SsGI and our unique sequences using Pearson's chi-square test. As described previously [27], a particular GO term can be viewed as a function that maps gene $G$ in go $(G)=0$ or 1 , according to the corresponding GO term. The null hypothesis of no association between gene lists and a particular GO term is translated into equal distributions of binary random variables. Only the list of genes annotated with GO terms was counted for the test. A Bonferroni correction [28] was applied to correct the multiple test problems.

To identify putative novel transcripts, SsGI sequences (Release 11.0) and our unique sequences were compared using the stand-alone BLAST program. Sequences with no BLAST hits represented putative novel transcripts. Some of the sequences were discarded if they contained fewer than $200 \mathrm{bp}$.

\section{Authors' contributions}

THK conceived of the study, participated in the coordination of bioinformatics activities and data analysis, and drafted the manuscript. NSK and JHO constructed the full-length enriched library. GWJ, BHC, and HYC participated in the sequence processing and library evaluation. KTL, HSP and HYL performed the high-throughput EST sequencing and quality assurance. DL, MJ, HYK, and HK performed the EST assembly, clustering, and annotation.

\section{References}

I. van Wijk HJ, Arts DJ, Matthews JO, Webster M, Ducro BJ, Knol EF: Genetic parameters for carcass composition and pork quality estimated in a commercial production chain. J Anim Sci 2005, 83:324-333.

2. Huff-Lonergan E, Baas TJ, Malek M, Dekkers JC, Prusa K, Rothschild MF: Correlations among selected pork quality traits. J Anim Sci 2002, 80:617-627.

3. Fahrenkrug SC, Smith TP, Freking BA, Cho J, White J, Vallet J, Wise T, Rohrer G, Pertea G, Sultana R, Quackenbush J, Keele JW: Porcine gene discovery by normalized cDNA-library sequencing and EST cluster assembly. Mamm Genome 2002, 13:475-478.

4. Tuggle CK, Schmitz CB: Cloning and characterization of pig muscle cDNAs by an expressed sequence tag approach. Anim Biotechnol 1994, 5: I-I3.

5. Wintero AK, Fredholm M, Davies W: Evaluation and characterization of a porcine small intestine cDNA library: analysis of 839 clones. Mamm Genome 1996, 7:509-5I7.

6. Bertani GR, Johnson RK, Robic A, Pomp D: Mapping of porcine ESTs obtained from the anterior pituitary. Anim Genet 2003, 34: $132-134$

7. Mikawa A, Suzuki H, Suzuki K, Toki D, Uenishi H, Awata T, Hamasima $\mathrm{N}$ : Characterization of 298 ESTs from porcine back fat tissue and their assignment to the SSRH radiation hybrid map. Mamm Genome 2004, 15:315-322.

8. Nobis W, Ren X, Suchyta SP, Suchyta TR, Zanella AJ, Coussens PM: Development of a porcine brain cDNA library, EST database, and microarray resource. Physiol Genomics 2003, 16:153-159.

9. Ponsuksili S, Wimmers K, Schellander K: Application of differential display RT-PCR to identify porcine liver ESTs. Gene 200I, 280:75-85.

10. Davoli R, Zambonelli P, Bigi D, Fontanesi L, Russo V: Analysis of expressed sequence tags of porcine skeletal muscle. Gene 1999, 233:181-188.

II. Davoli R, Fontanesi L, Zambonelli P, Bigi D, Gellin J, Yerle M, Milc J, Braglia S, Cenci V, Cagnazzo M, Russo V: Isolation of porcine expressed sequence tags for the construction of a first genomic transcript map of the skeletal muscle in pig. Anim Genet 2002, 33:3-18.

12. Yao J, Coussens PM, Saama P, Suchyta S, Ernst CW: Generation of expressed sequence tags from a normalized porcine skeletal muscle cDNA library. Anim Biotechnol 2002, 13:21 I-222.

13. Rink A, Santschi EM, Beattie CW: Normalized cDNA libraries from a porcine model of orthopedic implant-associated infection. Mamm Genome 2002, 13:198-205.

14. Smith TP, Fahrenkrug SC, Rohrer GA, Simmen FA, Rexroad CE, Keele JW: Mapping of expressed sequence tags from a porcine early embryonic cDNA library. Anim Genet 2001, 32:66-72.

15. Tuggle CK, Green JA, Fitzsimmons C, Woods R, Prather RS, Malchenko S, Soares BM, Kucaba T, Crouch K, Smith C, Tack D, Robinson N, O'Leary B, Scheetz T, Casavant T, Pomp D, Edeal BJ, Zhang Y, Rothschild MF, Garwood K, Beavis W: EST-based gene discovery in pig: virtual expression patterns and comparative mapping to human. Mamm Genome 2003, I 4:565-579.

16. Caetano AR, Johnson RK, Pomp D: Generation and sequence characterization of a normalized cDNA library from swine ovarian follicles. Mamm Genome 2003, 14:65-70.

17. Whitworth K, Springer GK, Forrester LJ, Spollen WG, Ries J, Lamberson WR, Bivens N, Murphy CN, Mathialagan N, Green JA, Prather RS: Developmental expression of $\mathbf{2 4 8 9}$ gene clusters during pig embryogenesis: an expressed sequence tag project. Biol Reprod 2004, 71 : 1230-1243.

18. Stapleton M, Carlson J, Brokstein P, Yu C, Champe M, George R, Guarin H, Kronmiller B, Pacleb J, Park S, Wan K, Rubin GM, Celniker SE: A Drosophila full-length cDNA resource. Genome Biol 2002, 3:RESEARCH0080.

19. Uenishi H, Eguchi T, Suzuki K, Sawazaki T, Toki D, Shinkai H, Okumura N, Hamasima N, Awata T: PEDE (Pig EST Data Explorer): construction of a database for ESTs derived from porcine full-length cDNA libraries. Nucleic Acids Res 2004, 32:D484-488. 
20. Fujisaki S, Sugiyama A, Eguchi $T$, Watanabe $Y$, Hiraiwa $H$, Honma $D$, Saito T, Yasue H: Analysis of a full-length cDNA library constructed from swine olfactory bulb for elucidation of expressed genes and their transcription initiation sites. J Vet Med Sci 2004, 66: 15-23.

21. Oh JH, Kim YS, Kim NS: An improved method for constructing a full-length enriched cDNA library using small amounts of total RNA as a starting material. Exp Mol Med 2003, 35:586-590.

22. Maruyama K, Sugano S: Oligo-capping: a simple method to replace the cap structure of eukaryotic mRNAs with oligoribonucleotides. Gene 1994, I38: I7I-174.

23. $\mathrm{Oh} J \mathrm{H}$, Sohn HY, Kim JM, Kim YS, Kim NS: Construction of multipurpose vectors, pCNS and pCNS-D2, are suitable for collection and functional study of large-scale cDNAs. Plasmid 2004, 5I:217-226.

24. Soares MB, Bonaldo MF, Jelene P, Su L, Lawton L, Efstratiadis A: Construction and characterization of a normalized cDNA library. Proc Natl Acad Sci USA 1994, 9 I:9228-9232.

25. Ewing B, Green P: Base-calling of automated sequencer traces using phred. II. Error probabilities. Genome Res 1998, 8:186-194.

26. Huang $X$, Madan A: CAP3: A DNA sequence assembly program. Genome Res 1999, 9:868-877.

27. Zhong S, Storch KF, Lipan O, Kao MC, Weitz CJ, Wong WH: GoSurfer : A Graphical Interactive Tool For Comparative Analysis of Large Gene Sets in Gene Ontologytrade mark Space. Appl Bioinformatics 2004, 3:26I-264.

28. Bonferroni CE: Teoria statistica delle classi e calcolo delle probabilit? Volume 8. Pubblicazioni del R Istituto Superiore di Scienze Economiche e Commerciali di Firenze; 1936:3-62.

29. Quackenbush J, Liang F, Holt I, Pertea G, Upton J: The TIGR gene indices: reconstruction and representation of expressed gene sequences. Nucleic Acids Res 2000, 28: |4|-| 45

30. Anderson L: Genetic dissection of phenotypic diversity in farm animals. Nature Genet 200I, 2:130-138.

31. Wayne ML, Mclntyre LM: Combining mapping and arraying: An approach to candidate gene identification. Proc Natl Acad Sci USA 2002, 99: 14903-14906.

32. Suzuki Y, Yoshitomo-Nakagawa K, Maruyama K, Suyama A, Sugano S: Construction and characterization of a full length-enriched and a 5'-end-enriched cDNA library. Gene 1997, 200:149-156.

33. Kato S, Sekine S, Oh SW, Kim NS, Umezawa Y, Abe N, YokoyamaKobayashi M, Aoki T: Construction of a human full-length cDNA bank. Gene 1994, 150:243-250.

34. Edery I, Chu LL, Sonenberg N, Pelletier J: An efficient strategy to isolate full-length cDNAs based on an mRNA cap retention procedure (CAPture). Mol Cell Biol 1995, 15:3363-3371.

35. Carninci P, Kvam C, Kitamura A, Ohsumi T, Okazaki Y, Itoh M, Kamiya M, Shibata K, Sasaki N, Izawa M, Muramatsu M, Hayashizaki Y, Schneider C: High-efficiency full-length cDNA cloning by biotinylated CAP trapper. Genomics 1996, 37:327-336.

36. Suzuki $Y$, Ishihara $D$, Sasaki $M$, Nakagawa $H$, Hata $H$, Tsunoda $T$, Watanabe M, Komatsu T, Ota T, Isogai T, Suyama A, Sugano S: Statistical analysis of the $5^{\prime}$ untranslated region of human mRNA using "Oligo-Capped" cDNA libraries. Genomics 2000, 64:286-297.

37. Suzuki $Y$, Sugano S: Construction of a full-length enriched cDNA libraries. The oligo-capping method. Methods Mol Biol 200I, I75:143-153.

38. Jiang $\mathrm{H}$, Whitworth KM, Bivens NJ, Ries JE, Woods RJ, Forrester LJ, Springer GK, Mathialagan N, Agca C, Prather RS, Lucy MC: Largescale generation and analysis of expressed sequence tags from porcine ovary. Biol Reprod 2004, 71: I99|-2002.

39. Dvorak CM, Hyland KA, Machado JG, Zhang Y, Fahrenkrug SC, Murtaugh MP: Gene discovery and expression profiling in porcine Peyer's patch. Vet Immunol Immunopathol 2005, 105:30I-3I5.

40. Battini R, Ferrari S, Kaczmarek L, Calabretta B, Chen ST, Baserga R: Molecular cloning of a cDNA for a human ADPIATP carrier which is growth-regulated. J Biol Chem 1987, 262:4355-4359.

4I. Zhao SH, Nettleton D, Liu W, Fitzsimmons C, Ernst CW, Raney NE, Tuggle CK: Complementary DNA macroarray analyses of differential gene expression in porcine fetal and postnatal muscle. J Anim Sci 2003, 81:2179-2188.

42. Audic S, Claverie JM: The significance of digital gene expression profiles. Genome Res 1997, 7:986-995.
43. Stekel DJ, Git Y, Falciani F: The comparison of gene expression from multiple cDNA libraries. Genome Res 2000, 10:2055-206I.

44. Yu J, Farjo R, MacNee SP, Baehr W, Stambolian DE, Swaroop A: Annotation and analysis of 10,000 expressed sequence tags from developing mouse eye and adult retina. Genome Biol 2003, 4:R65.

45. Bai Q, McGillivray C, da Costa N, Dornan S, Evans G, Stear MJ, Chang KC: Development of a porcine skeletal muscle cDNA microarray: analysis of differential transcript expression in phenotypically distinct muscles. BMC Genomics 2003, 4:8.

46. Niewold TA, Kerstens HH, vander Meulen J, Smits MA, Hulst MM: Development of a porcine small intestinal cDNA microarray: characterization and functional analysis of the response to enterotoxigenic E. coli. Vet Immunol Immunopathol 2005, I 05:317-329.

47. Caetano AR, Johnson RK, Ford JJ, Pomp D: Microarray profiling for differential gene expression in ovaries and ovarian follicles of pigs selected for increased ovulation rate. Genetics 2004, 168:1529-1537.

48. Smith DM, Lunney JK, Martens GW, Ando A, Lee JH, Ho CS, Schook L, Renard C, Chardon P: Nomenclature for factors of the SLA class-I system, 2004. Tissue Antigens 2005, 65: I36-149.

49. Weisberg SP, McCann D, Desai M, Rosenbaum M, Leibel RL, Ferrante AW Jr: Obesity is associated with macrophage accumulation in adipose tissue. J Clin Invest 2003, I I 2:1796- I808.

50. Xu H, Barnes GT, Yang Q, Tan G, Yang D, Chou CJ, Sole J, Nichols $A$, Ross JS, Tartaglia LA, Chen H: Chronic inflammation in fat plays a crucial role in the development of obesity-related insulin resistance. / Clin Invest 2003, I I 2: |82 |- | 830.

51. QTL database [http://www.animalgenome.org]
Publish with Bio Med Central and every scientist can read your work free of charge

"BioMed Central will be the most significant development for disseminating the results of biomedical research in our lifetime."

Sir Paul Nurse, Cancer Research UK

Your research papers will be:

- available free of charge to the entire biomedical community

- peer reviewed and published immediately upon acceptance

- cited in PubMed and archived on PubMed Central

- yours - you keep the copyright 